\title{
Tuberous sclerosis: a new estimate of prevalence within the Oxford region
}

\author{
A HUNT* AND R H LINDENBAUM $\dagger$
}

From * the Human Development Research Unit, Park Hospital for Children, Old Road, Headington, Oxford; and $\dagger$ Department of Medical Genetics, Churchill Hospital, Headington, Oxford.

SUMMARY Within the counties administered by the Oxford Regional Health Authority (population 2328 100) the prevalence of tuberous sclerosis was estimated as 1 in 29900 for persons under 65 years of age. For the population below 30 years of age the prevalence was 1 in 21500 and for children under 5 years 1 in 15 400. Cases were ascertained through the records of the Department of Medical Genetics at Oxford and the Tuberous Sclerosis Association of Great Britian and also by a questionnaire sent to selected consultants within the region. A previous estimate of prevalence within the region was 1 in 100000 . This study suggests that the prevalence at birth might be even higher than 1 in 15000 .

Although recognised and described by Bourneville ${ }^{1}$ over a century ago, tuberous sclerosis may still be called 'a rare disorder'. What now seem to be low estimates of prevalence were made by Stevenson and Fisher ${ }^{2}$ in Northern Ireland ( 1 in 150000$)$ and by Nevin and Pearce $^{3}$ working roughly within the bounds of the present Oxford region (1 in 100 000). More recent estimates of prevalence are higher, and include those of Zaremba ${ }^{4}(1$ in 23000 ) based on a survey of institutionalised mentally retarded people in Poland, Donegani et $a l^{5}$ ( 1 in 10000 ) estimated from routine necropsies in Switzerland, and Fleury et $\mathrm{l}^{6}(1$ in 30000$)$ in Holland.

Paediatricians now recognise tuberous sclerosis as a significant cause of infantile spasms and developmental handicap. ${ }^{7-9}$ The white skin macule, which usually appears before the facial angiofibroma (adenoma sebaceum), is established as a useful early sign of the disorder. ${ }^{10}{ }^{11}$ Use of computerised tomographic scanning improves early detection and accurate diagnosis in both symptomatic and asymptomatic persons. The autosomal dominant mode of transmission is well established. Although about $80 \%$ of cases are estimated to be new mutations, ${ }^{12} 13$ asymptomatic carriers of the gene without serious health problems are often found among sibs or parents of severely handicapped children.

No study can identify all the asymptomatic carriers in the general population. The present one attempts to reassess the situation within the Oxford

Received for publication 29 November 1983.

Accepted for publication 4 January 1984 . region with the help of relatively 'new' physical signs, such as white macules and enamel pits, ${ }^{14}$ and new technology, such as CT scanning, combined with a family approach and home visiting. The study drew on the records of the Department of Medical Genetics at Oxford and the Tuberous Sclerosis Association, and collected further cases by a questionnaire sent to consultants in nine specialities. Only at the end of the work was use made of the files of Nevin and Pearce, as a check against omissions.

\section{Method}

An attempt was made to identify all cases of tuberous sclerosis within the geographical limits of the Oxford Regional Health Authority who were alive on the survey date of 31.8 .82 . Sufficient contact had been maintained with families to be sure that the cited persons were alive on this date. Where doubt existed further enquiries were made. Of the 68 affected persons, 51 were visited personally by one of the authors. Apart from the cases separately annotated (see appendix) all the cases seen satisfied the diagnostic criteria suggested by Gomez ${ }^{15}$ in 1979 , having at least one primary or two secondary signs of tuberous sclerosis. Gomez's criteria did not include epileptic seizures other than infantile spasms, mental retardation, gingival fibromata, or congenital enamel pits, and the hypomelanotic macules are scored as a secondary sign only.

Further cases were ascertained by a questionnaire 
sent to all 79 of the regional consultants in paediatrics, dermatology, neurology, neurosurgery, neuropathology, mental handicap, child psychiatry, ophthalmology, and renal medicine. Lastly the files of Nevin and Pearce's 1968 survey $^{3}$ were re-examined and compared with the patients listed in this 1982 survey.

The most recent information on the population of the Oxford region was obtained from OPCS figures available through the Regional Health Authority. The latest figures related to 1981 and included a partitioning of the total population into age groups or cohorts, namely less than 1 year, 1 to 4 years, 5 to 14 years, and so on. Cases ascertained in this present survey were partitioned into corresponding age groups and prevalences separately estimated within these groups and for the total population (2 328 100).

\section{Results}

A total of 68 cases was ascertained in all. Many were ascertained independently from several sources (see appendix). There were 30 males and 37 females. In one family (case numbers 34,35 , and 65 in the appendix) it could not be decided which parent of three cases of tuberous sclerosis, one already dead, actually carried the gene.

TABLE 1 Tuberous sclerosis: prevalence of mental handicap by age.

\begin{tabular}{lclll}
\hline Age $(y r)$ & \multicolumn{3}{l}{ Mental handicap } & \\
\cline { 2 - 5 } & Severe & Mild & None & Not known \\
\hline$<5$ & 9 & 1 & 0 & 0 \\
$5-14$ & 8 & 4 & 5 & 2 \\
$15-29$ & 15 & 1 & 3 & 1 \\
$30-44$ & 4 & 1 & 8 & 1 \\
$45+$ & 0 & 1 & 4 & 0 \\
All ages & 36 & 8 & 20 & 4 \\
\hline
\end{tabular}

TABLE 2 Case numbers of family members with tuberous sclerosis.

\begin{tabular}{lll}
\hline 2 family members & 3 family members & 4 family members \\
\hline 1458 & 343565 & 20212257 \\
2563 & 404156 & 10616268 \\
4766 & & \\
\hline
\end{tabular}

The numbers refer to cases listed in the appendix.
Forty-four cases were known to the Department of Medical Genetics (DMG), 28 cases were known to the Tuberous Sclerosis Association (TSA) ${ }^{16}$ and 13 cases were identified by questionnaire alone (replies were received from 62 of 79 consultants contacted). Nine cases from Nevin and Pearce were again identified in this survey. Only one had been referred again to DMG during the last 10 years, but four others were known to the TSA and four were reidentified by questionnaire alone. The remaining nine cases of Nevin and Pearce had died meanwhile or were otherwise lost to follow-up.

Details of referring consultants and of identifications made by questionnaire are listed in the appendix. Paediatricians referred the greatest number of cases to DMG, a total of 17 , with nine other cases recognised among family members through such referrals. Of the cases aged over 45 , three out of five were identified only through referral of their ill or handicapped children. Nine of the 13 cases identified by questionnaire alone were older persons, but four cases were under 15 years.

Fifty-one of the recorded cases were seen personally by one or both authors. The remaining 17 cases included eight reported by questionnaire alone and three cases known also to Nevin and Pearce. In all cases not seen personally, the diagnosis was considered well established by specialist clinicians.

Thirty-six persons suffered severe mental handicap, eight were mildly handicapped, and 20 not at all. There was no knowledge of the mental state in the remaining four cases. Table 1 shows that in the youngest age groups virtually all cases were severely mentally handicapped, while in the over 45 s no case of severe handicap was identified.

The 68 cases comprised 48 unrelated subjects and seven families with more than one affected. The family groups consisted of one, two, or three affected sibs plus an affected parent (table 2 ). In one family there were three generations of people with tuberous sclerosis, with only the child in the third generation showing mild mental handicap.

Thirty-four cases were thought to have arisen as new mutations and 17 received the tuberous sclerosis gene from an affected parent. In 17 cases it could not be decided whether the condition represented a mutation or was transmitted from a parent. Very

TABLE 3 Tuberous sclerosis: prevalence by age in Oxford region (as on 31.8.82).

\begin{tabular}{|c|c|c|c|c|c|c|c|c|}
\hline $\begin{array}{l}\text { Born from } \\
\text { To } \\
\text { Age }(\mathrm{yr}) \\
\text { No of cases } \\
\text { Regional population }(1000 \mathrm{~s}) \\
\text { Prevalence }(1000 \text { s/case })\end{array}$ & $\begin{array}{c}9 \cdot 81 \\
8 \cdot 82 \\
<1 \\
2 \\
32 \cdot 1 \\
16 \cdot 1\end{array}$ & $\begin{array}{r}9 \cdot 77 \\
8 \cdot 81 \\
1-4 \\
8 \\
122 \cdot 2 \\
15 \cdot 3\end{array}$ & $\begin{array}{r}9 \cdot 67 \\
8 \cdot 77 \\
5-14 \\
19 \\
349 \cdot 8 \\
18 \cdot 4\end{array}$ & $\begin{array}{r}9 \cdot 52 \\
8 \cdot 67 \\
15-29 \\
20 \\
551 \cdot 6 \\
27 \cdot 6\end{array}$ & $\begin{array}{r}9 \cdot 37 \\
8 \cdot 52 \\
30-44 \\
14 \\
491 \cdot 0 \\
35 \cdot 1\end{array}$ & $\begin{array}{r}9 \cdot 17 \\
8 \cdot 37 \\
45-64 \\
5 \\
487 \cdot 6 \\
97 \cdot 5\end{array}$ & $\begin{array}{l}\text { bf } / \text { in } \\
8 \cdot 17 \\
65+ \\
0 \\
293 \cdot 8 \\
-\end{array}$ & $\begin{array}{c}68 \\
2328 \cdot 1 \\
34 \cdot 2\end{array}$ \\
\hline
\end{tabular}


TABLE 4 Tuberous sclerosis: prevalence by cumulative age groups in Oxford region (as on 31.8.82).

\begin{tabular}{|c|c|c|c|c|c|c|c|}
\hline $\begin{array}{l}\text { Age, cumulative years } \\
\text { No of cases } \\
\text { Regional population, cumulative (1000s) } \\
\text { Prevalence, cumulative } \\
\quad \text { (population } 1000 \text { s/case) }\end{array}$ & $\begin{array}{c}<1 \\
2 \\
32 \cdot 1\end{array}$ & $\begin{array}{l}<5 \\
10 \\
154 \cdot 3\end{array}$ & $\begin{array}{l}<15 \\
29 \\
504 \cdot 1\end{array}$ & $\begin{array}{l}<30 \\
49 \\
1055 \cdot 7\end{array}$ & $\begin{array}{l}<45 \\
63 \\
1546 \cdot 7\end{array}$ & $\begin{array}{l}<65 \\
68 \\
2034 \cdot 3\end{array}$ & $\begin{array}{l}\text { All ages } \\
68 \\
2328 \cdot 1\end{array}$ \\
\hline
\end{tabular}

often this uncertainty was due to insufficient investigation of the families concerned. Thus it was estimated that between $50 \%$ and $75 \%$ of cases represent new mutations (34/68 to $51 / 68$ cases).

The ascertained cases were grouped by age (appendix). Table 3 gives the prevalence by age groups, using the OPCS figures for the total population in the Oxford region. It is also of interest to consider prevalence by cumulative age groups and this is given in table 4.

\section{Discussion}

The prevalence of tuberous sclerosis in this study of the Oxford region was 1 in 34200 considering the whole population. However, for persons under the age of 45 the prevalence was 1 in 24600 , four times that found by Nevin and Pearce, and for persons under the age of 15 the prevalence was 1 in 17300 . In children under 5 it was 1 in 15400 .

Incomplete ascertainment in 1968 may have arisen in a number of ways and ascertainment in 1982 is also likely to be incomplete. In the youngest age groups incomplete ascertainment may arise through lack of symptoms which may appear later, such as epilepsy or mental retardation, or through lack of signs which can appear later such as facial angiofibroma or gingival fibromata. In the absence of clear physical signs of tuberous sclerosis slight symptoms such as minimal fits or mild retardation may not suggest the diagnosis. Signs themselves may be hard to recognise, such as congenital forehead plaques, hypopigmented macules on pale skin, and early or mild fibroadenomata. Symptoms and signs may be obvious, but the diagnosis of tuberous sclerosis may not have been considered or established. Table 1 shows that only severely handicapped children were likely to be identified below the age of 5 years.

Older children and adults with tuberous sclerosis may suffer no neurological handicap. In some the skin signs are poorly developed or non-existent, or a facial rash is regarded as mere acne. Neurological handicap, when mild, may be regarded as environmental or social in origin. Some persons suffer serious problems arising from tuberous sclerosis, such as renal angiomyolipoma, but the diagnosis of tuberous sclerosis is not considered. Family aspects of the disorder may be ignored and affected first degree relatives not identified.
All these factors are likely to have operated more strongly in 1968 than in 1982, but there is evidence that they are still operating and present ascertainment remains incomplete. The fullest ascertainment would be expected in the younger age groups where most of the diagnostic activity is concentrated. Tables 3 and 4 show clearly a higher prevalence in the younger age groups; after the age of 30 the prevalence drops considerably. This may reflect less accurate diagnosis within the older age groups, but the lower reported prevalence is probably also due in part to excess early mortality from related problems, like renal, respiratory, or cardiac failure, brain tumour, or status epilepticus, which may cause death in young or middle aged adults. Even our estimates of prevalence in childhood are underestimates of birth prevalence, since some children do die from tuberous sclerosis in the first years of life or, although affected, are not referred then.

Given these difficulties in making a full ascertainment of tuberous sclerosis it is of some interest that the proportion of severely handicapped cases ( 36 out of 68 , that is $53 \%$ ) is close to that of other published series. ${ }^{15}$

If it is assumed that nearly all of the incompletely investigated cases represent new mutations then 51 of 68 , that is $75 \%$ of cases, are new mutations. Thus the mutation rate can be calculated using 1 in 15000 as an estimate of prevalence: $75 / 100 \times 1 / 2 \times 1 / 15000$ $=2.5 \times 10^{-5}\left(\mathrm{SE}=3 \cdot 2 \times 10^{-6}\right)$.

It appears that only severely handicapped children are diagnosed below the age of 5 years, but there are at least 20 out of 58 cases in the older age groups ( 5 years or over) who are without mental handicap. This suggests that for the 10 cases diagnosed below 5 years there are in this age group another five cases without handicap, that is, the true prevalence in the under 5s may not be 1 in 15000 but nearer to 1 in 10000.

The method of estimating prevalence by age groups, separately and cumulatively, seems particularly appropriate and useful when dealing with a condition associated with an increased risk of early mortality.

This work was supported by a grant from the Tuberous Sclerosis Association of Great Britain. 


\section{References}

1 Bourneville DM. Sclérose tubéreuse des circonvolutions cérébrales: idiotie et épilepsie hémiplégique. Arch Neurol (Paris) $1880 ; 1: 81-91$.

2 Stevenson NC, Fisher OD. Frequency of epiloia in Northern Ireland. Br J Prev Soc Med 1956;10:134-5.

3 Nevin NC, Pearce MG. Diagnostic and genetical aspects of tuberous sclerosis. J Med Genet 1968;5:273-80.

* Zaremba J. Tuberous sclerosis: a clinical and genetical investigation. J Ment Defic Res 1968;12:63-80.

5 Donegani G, Gratarolla FR, Wildi E. Tuberous sclerosis. In: Vinken PJ, Bruyn $\mathrm{GW}$, eds. The phakomatoses. Handbook of Clinical Neurology. Vol 14. Amsterdam: North-Holland, 1972:340-89.

6 Fleury P, de Groot MP, Delleman JW, Verbeeten B Jr, Frankenmolen-Witkiezwicz IM. Tuberous sclerosis: the incidence of sporadic versus familial cases. Brain Dev $1980 ; 2: 107-17$.

7 Pampiglione G, Pugh E. Infantile spasms and subsequent appearance of tuberous sclerosis syndrome. Lancet 1975; 2:1046.

8 Pampiglione G, Moynahan EJ. The tuberous sclerosis syndrome: clinical and EEG studies in 100 children. $J$ Neurol Neurosurg Psychiatry 1976;39:666-73.
9 O'Donohue NV. Epilepsies in childhood: London: Butterworths, 1979:30-43.

10 Critchley M, Earl CJC Tuberous sclerosis and allied conditions. Brain 1932;55:311-46.

11 Gold AP, Freeman JM. Depigmented nevi: the earliest sign of tuberous sclerosis. Pediatrics 1965;35:1003-5.

12 Lagos JC, Gomez MR. Tuberous sclerosis: reappraisal of a clinical entity. Proc Mayo Clin 1967;42:26-49.

13 Bundey S, Evans K. Tuberous sclerosis, a genetic study. J Neurol Neurosurg Psychiatry 1969;32:591-603.

14 Ligidakis NA, Lindenbaum RH. Enamel defects in tuberous sclerosis: a clinical and scanning EM study. Presentation at Symposium on Autosomal Heterozygosity, Nijmegen, Holland, May 1983. Summary in Clin Genet $1983 ; 24: 288$.

15 Gomez MR. Clinical experience at Mayo Clinic. In: Gomez MR, ed. Tuberous sclerosis. New York: Raven Press, 1979:11-26.

16 Hunt A. Tuberous sclerosis: a survey of 97 cases. Dev Med Child Neurol 1983 ;25:346-57.

Correspondence and requests for reprints to $\mathrm{Dr} \mathrm{R} \mathrm{H}$ Lindenbaum, Department of Medical Genetics, Churchill Hospital, Headington, Oxford OX3 7LJ.

APPENDIX Cases of tuberous sclerosis ascertained in survey of the Oxford region and mode of ascertainment.

\begin{tabular}{|c|c|c|c|c|c|c|c|c|c|}
\hline Case No & MS & $H h$ & $D O B$ & $\operatorname{sex}$ & ascDMG & $\operatorname{ascTSA}$ & $\operatorname{asc} Q U E$ & NevPea & Seen by \\
\hline \multicolumn{10}{|c|}{ Born 9.81-8.82: age below 1 year } \\
\hline 01 & M & $\mathbf{H}$ & $3 / 82$ & $\mathbf{F}$ & $\mathbf{P}$ & TSA & - & - & RL AH \\
\hline 02 & $\mathbf{M}$ & $\mathbf{H}$ & $5 / 82$ & $\mathbf{F}$ & $\mathbf{P}$ & TSA & - & - & $\mathbf{R L}$ \\
\hline \multicolumn{10}{|c|}{ Born 9.77-8.81: $1-4$ years old } \\
\hline 03 & $\mathbf{M}$ & $\mathrm{H}$ & $12 / 80$ & $\mathrm{~F}$ & $\mathbf{P}$ & TSA & $\mathbf{P}$ & 一 & RL AH \\
\hline 04 & $\mathbf{M}$ & $\mathbf{H}$ & $7 / 81$ & $\mathbf{M}$ & $\mathbf{P}$ & TSA & - & - & RL AH \\
\hline 05 & $\mathrm{~m}$ & $\mathbf{H}$ & $2 / 80$ & $\mathbf{F}$ & - & TSA & $\mathbf{P}$ & $\ldots$ & RL AH \\
\hline 06 & $\mathbf{M}$ & $\mathbf{H}$ & $5 / 79$ & $\mathbf{M}$ & $\mathbf{P}$ & 一 & - & - & $\mathbf{R L}$ \\
\hline 07 & $\mathbf{M}$ & $\mathbf{H}$ & $9 / 79$ & $\mathbf{M}$ & $\mathbf{P}$ & TSA & $\mathbf{P}$ & - & RL AH \\
\hline 08 & M & $\mathbf{H}$ & $12 / 78$ & $\mathrm{~F}$ & $\mathbf{P}$ & TSA & $2 \mathbf{P}$ & - & RL AH \\
\hline 09 & & $\mathbf{H}$ & $8 / 81$ & $\mathbf{F}$ & $\mathbf{P}$ & - & - & - & RL \\
\hline 10 & $\mathbf{S}$ & $\mathrm{h}$ & $4 / 81$ & $\mathbf{M}$ & (P) & 一 & - & - & $\mathbf{R L}$ \\
\hline \multicolumn{10}{|c|}{ Born 9.67-8.77: 5-14 years old } \\
\hline 11 & $\mathbf{M}$ & $\mathbf{H}$ & $12 / 71$ & $\mathbf{M}$ & $\mathbf{P}$ & TSA & $2 \mathbf{P}$ & - & $\mathbf{R L}$ \\
\hline 12 & $\mathrm{~m}$ & $\mathbf{H}$ & $2 / 70$ & $\mathbf{F}$ & MH, P & TSA & $\mathbf{P}$ & - & RL AH \\
\hline 13 & $\mathbf{M}$ & $\mathrm{H}$ & $2 / 70$ & $\mathbf{M}$ & $\mathbf{P}$ & TSA & $\mathbf{P}$ & - & RL AH \\
\hline 14 & $\mathrm{~S}$ & $\mathrm{~h}$ & $6 / 71$ & $\mathbf{M}$ & MH & - & P, NP & - & $\mathbf{R L}$ \\
\hline 15 & & & $10 / 72$ & $\mathbf{M}$ & - & 一 & D & ... & - \\
\hline 16 & $\mathbf{M}$ & o & $12 / 70$ & $\mathbf{M}$ & $\mathbf{A H}$ & TSA & P, D & - & RL AH \\
\hline 17 & & & $4 / 74$ & $\mathbf{F}$ & - & - & $\mathbf{P}$ & - & - \\
\hline 18 & $\mathbf{M}$ & $\mathrm{H}$ & $5 / 77$ & $\mathbf{F}$ & $\mathbf{P}$ & TSA & P, D & - & RL AH \\
\hline 19 & $\mathbf{M}$ & H & $8 / 71$ & $\mathbf{M}$ & $\mathbf{P}$ & TSA & $\mathrm{P}, 2 \mathrm{NS}$ & - & RL AH \\
\hline 20 & $\mathrm{~s}$ & $\mathrm{~h}$ & $6 / 73$ & $\mathbf{F}$ & (P) & - & - & - & $R L$ \\
\hline 21 & $\mathrm{~s}$ & o & $3 / 76$ & $\mathbf{F}$ & (P) & - & - & 一 & $\mathbf{R L}$ \\
\hline 22 & s & o & $8 / 77$ & $\mathbf{M}$ & $\mathbf{P}$ & - & - & - & RL \\
\hline 23 & M & o & $4 / 72$ & $\mathbf{M}$ & GP & TSA & - & $\ldots$ & RL AH \\
\hline 24 & $\mathbf{M}$ & $\mathrm{H}$ & $9 / 71$ & $\mathrm{~F}$ & $\mathbf{P}$ & TSA & $\mathbf{P}$ & - & RL AH \\
\hline 25 & $\mathrm{~s}$ & $\mathrm{~h}$ & $9 / 67$ & $\mathbf{M}$ & - & - & $\mathbf{P}$ & -. & - \\
\hline 26 & M & $\mathrm{H}$ & $10 / 67$ & $\mathrm{~F}$ & MH & TSA & D & - & RL AH \\
\hline 27 & & $h$ & $3 / 71$ & $\mathbf{M}$ & PS & - & - & - & RL \\
\hline 28 & & $\mathbf{H}$ & $1 / 75$ & $\mathbf{M}$ & - & TSA & - & - & AH \\
\hline 29 & & o & 1973 & $\mathbf{M}$ & - & - & NS & - & - \\
\hline \multicolumn{10}{|c|}{ Born 9.52-8.67: $15-19$ years old } \\
\hline 30 & $\mathbf{M}$ & $\mathrm{H}$ & $11 / 62$ & $\mathbf{F}$ & MH & - & $2 \mathbf{P}$ & - & RL \\
\hline 31 & & $\mathrm{H}$ & $7 / 56$ & $\mathbf{F}$ & MH & 一 & MH & - & AH \\
\hline 32 & & & $1 / 66$ & $\mathbf{F}$ & - & - & $\mathbf{P}$ & - & - \\
\hline 33 & & $\mathrm{H}$ & $6 / 66$ & $\mathbf{M}$ & - & TSA & $2 \mathrm{MH}$ & 一 & $\mathbf{R L}$ \\
\hline 34 & S & $\mathrm{H}$ & $6 / 59$ & $\mathbf{F}$ & GP & - & $2 \mathrm{MH}$ & - & $\mathbf{R L}$ \\
\hline 35 & $\mathbf{S}$ & H & $3 / 63$ & $\mathrm{~F}$ & GP & - & $2 \mathrm{MH}$ & - & $\mathbf{R L}$ \\
\hline 36 & $\mathrm{~m}$ & $\mathbf{H}$ & $7 / 60$ & $\mathrm{~F}$ & AH & TSA & D & - & - \\
\hline
\end{tabular}


APPENDIX-continued

37
38
39
40
41
42
43
44
45
46
47
48
49

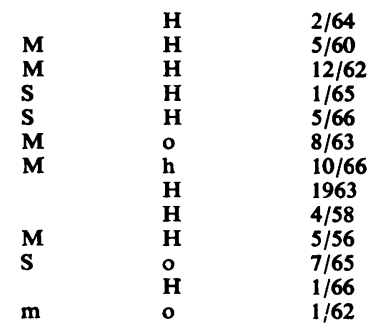

$\mathbf{M}$
$\mathbf{F}$
$\mathbf{F}$
$\mathbf{F}$
$\mathbf{F}$
$\mathbf{F}$
$\mathbf{F}$
$\mathbf{F}$
$\mathbf{F}$
$\mathbf{M}$
$\mathbf{M}$
$\mathbf{M}$
$\mathbf{F}$

\begin{tabular}{lll} 
P, GP & - & MH, D \\
P, D, GP & - & 2P \\
- & TSA & P \\
$\overline{\text { PS }}$ & TSA & P, MH \\
MH & TSA & PS \\
- & PS \\
MH & TSA & - \\
N & - & - \\
\hline D & - & - \\
TSA & N
\end{tabular}

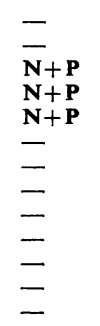

RL

Born 9.37-9.52: $30-44$ years old

50

$\mathbf{M}$
$\mathbf{M}$
$\mathbf{M}$

$\mathbf{h}$
$\mathbf{H}$
$\mathbf{H}$
$\mathbf{H}$

$9 / 45$

$11 / 46$

$3 / 45$

$7 / 49$

$9 / 49$

54

$\mathbf{M}$
$\mathbf{S}$
$\mathbf{M}$
$\mathbf{S}$
$\mathbf{S}$
$\mathbf{S}$
$\mathbf{S}$

$12 / 44$

$3 / 39$

$11 / 43$

$6 / 40$

$12 / 42$

$7 / 42$

$1 / 52$

$7 / 50$

$\begin{array}{lll}\mathbf{M} & - & \\ \mathbf{M} & - & \\ \mathbf{F} & - & \\ \mathbf{M} & - & \\ \mathbf{F} & - & \\ \mathbf{F} & - & \\ \mathbf{M} & \mathbf{T} & \\ \mathbf{F} & \mathbf{( P )} & \\ \mathbf{M} & \mathbf{P}) & \\ \mathbf{F} & - & \\ \mathbf{F} & - & \\ \mathbf{F} & \text { (P) } & \\ \mathbf{M} & \text { (P) } & \end{array}$

$\begin{array}{ll}- & \mathbf{P} \\ - & \text { MH } \\ - & \end{array}$

TSA

二

TSA

-

I

61

63

$3 / 41$

2MH

D

MH

-

$\bar{z}$

$\overline{\mathbf{N}}$

-

(P)

$-$

-

$\begin{array}{ll}\overline{\text { (GP) }} & = \\ \mathbf{N} & = \\ \text { (Other) } & = \\ \text { (P) } & \end{array}$

$\begin{array}{ll}\mathbf{N} & \mathbf{N}+\mathbf{P} \\ \overline{\mathbf{D}} & =\end{array}$

$\mathbf{R L}$
$\mathbf{R L}$
$\mathbf{R L}$
$\overline{\mathbf{R L}}$

Born up to and including 8.17: 65 years and over

$\begin{array}{ll}12 / 32 & M \\ 223 / 30 & ? \\ 9 / 25 & \text { M } \\ 1922 & \text { F } \\ 6 / 24 & \text { F }\end{array}$

$\begin{array}{ll}\mathbf{N}+\mathbf{P} & - \\ \mathbf{N}+\mathbf{P} & - \\ \mathbf{N}+\mathbf{P} & \mathbf{R L} \\ \mathbf{N}+\mathbf{P} & \mathbf{R L} \\ - & - \\ \overline{\mathbf{N}}+\mathbf{P} & \overline{\mathbf{R} L} \\ - & \mathbf{R L} \\ - & \mathbf{R L} \\ - & - \\ - & \overline{\mathbf{R}} \\ - & \mathbf{R L} \\ - & \mathbf{R L}\end{array}$

RL

AH

RL AH

RL AH

$\overline{R L} \mathbf{A H}$

AH

$\mathbf{L}^{\mathbf{A}}$

Born 9.17-8.37: 45-64 years old

$\begin{array}{llll}64 & \mathrm{~S} & \text { h } & 12 / 32 \\ 65 & \mathrm{M} & 0 & 223 / ' 30 \\ 66 & \mathrm{M} & 0 & 9 / 25 \\ 67 & & 0 & 1922 \\ 68 & M & 0 & 6 / 24\end{array}$

$\begin{array}{lll}\mathbf{M} & - & - \\ ? & \text { (GP) } & - \\ \mathbf{M} & \mathbf{N} & - \\ \mathbf{F} & \text { (Other) } & - \\ \mathbf{F} & \text { (P) } & -\end{array}$

No cases

$\mathbf{M}=$ mutant

$\mathbf{m}=$ ? mutant

$\mathbf{S}=$ segregant

$\mathrm{s}=$ ? segregant

$\mathbf{H}=$ severe mental handicap

$\mathbf{h}=$ mild mental handicap

$0=$ no mental handicap

ascDMG = ascertainment by Department of Medical Genetics.

ascTSA = ascertainment by Tuberous Sclerosis Association (membership list).

ascQUE = ascertainment by questionnaire.

NevPea $=$ found also in Nevin and Pearce 1968 files.

() means ascertained by family follow up with initial mode of referral in brackets.

In ascDMG or ascQUE columns, referring doctor as follows:

D dermatologist

GP general practitioner

MH mental handicap physician

Neurologist

NS neurosurgeon

P paediatrician

PS psychiatrist

No cases were ascertained through ophthalmologists or renal physicians. 


\section{Annotated cases}

Case 10 was referred for mild mental handicap with macrocephaly and mildly dilated ventricles but no other signs of TS on the CT brain scan. On examination he had a few white macules. His father (62) had gingival fibromata as the only sign of TS, but the father's sister (61) and the father's mother (68) had classical adenoma sebaceum, subungual fibromata, and other signs of TS. In this family no-one had severe mental handicap or had ever had a fit. The grandmother (68) was ascertained by questionnaire independently of the rest of the family and shortly before the grandchild (10) was seen in the Department of Medical Genetics.

Case 14 had skin signs more suggestive of the linear sebaceus naevus syndrome, with severe retardation and epilepsy problems in the first 2 years of life and a few enamel pits as seen in TS. Neurosurgery largely cured the epilepsy and the retardation, and the neuropathological findings were reported as typical of TS. The father (58) had skin signs similar to those in the son, but to a lesser degree, with no epilepsy or other handicaps.

Case 22 was referred by a paediatrician. He had suffered several grand mal convulsions at 3 years of age with no further fits in the following 2-year period. A sister (21) had a patch of shagreen skin, with typical histological changes observed at biopsy. She had no fits and no retardation, but there were one or possibly two white macules somewhat suggestive of TS.

Another sister (20) had suffered from mild retardation of unknown cause. There had been some twitching of a leg during the first 2 weeks of life, but no clear history of fits, and there were no obvious signs of TS. The mother (57) had no fits or handicap, but was observed to have a few gingival fibromata as in TS.

The mother's brother, living outside the region, suffered from severe epilepsy and mild retardation. $\mathrm{He}$ had undergone neurosurgery when aged 33 years for a congenital arteriovenous malformation. Other maternal relatives were said to have suffered from fits and brain damage.

Sisters 34 and 35 had classical skin signs of TS and were long term patients in hospital on account of severe mental handicap and behaviour problems. A brother had died almost 25 years previously with rhabdomyoma and heart failure at 3 months of age. Another brother died several months after the survey date, suffering from severe mental retardation of unknown cause, with gross scoliosis but no clear signs of TS in life or at necropsy. The parents were first cousins and no signs of TS were detected in either. However, no CT brain scans were performed and they were rather uncooperative in attempts to arrange other special investigations, such as fundoscopy with mydriatics or skull $x$-rays. Either we accept parental gonadal mosaicism, autosomal recessive determination of TS, or triple extramarital conception as explanation of this constellation of cases, or one parent, signless and symptomless, was carrying the TS gene. We preferred this latter explanation and listed a parent, 'mother/father', as case 65.

Case 67 would not be seen, but was reported to have typical adenoma sebaceum. Her daughter, dead at 20 , was seen by RL and had skin signs of TS together with severe involvement of heart, lungs, and kidneys. Both mother and daughter had had parathyroidectomy for endocrine secreting tumours.

Excluded from the survey was a child with intractable epilepsy with onset at 2 to 3 months and gross developmental retardation. He had an oval 'bald patch', $1 \times 1.5 \mathrm{~cm}$, in the left parietal area, reddishbrown in colour, and resembling the congenital forehead plaques sometimes seen in TS. There were no other signs of TS, and first degree relatives were also examined by $R L$ with negative result. The child died of epilepsy and pneumonia at 18 months and permission for necropsy was refused. He had been alive on the survey date. 